\title{
EDITORIAL
}

\section{ENFERMEDADES INFECCIOSAS EMERGENTES. ALERTA MUNDIAL, RESPUESTA MUNDIAL}

\author{
Juan Jesús Gestal Otero \\ Director General de Salud Pública. Consejería de Sanidad y Servicios Sociales. Junta de Galicia.
}

Cada siete de abril la OMS, conmemora la fecha de su constitución con la celebración del Día Mundial de la Salud en el que destaca un problema sanitario de interés general, en este año el elegido fueron las enfermedades infecciosas emergentes, con el lema: Alerta mundial, respuesta mundial.

El concepto de enfermedades infecciosas emergentes fue acuñado en 1992 por el Instituto de Medicina de los EEUU, para referirse a las enfermedades infecciosas descubiertas en los últimos años y a las ya conocidas consideradas controladas, en franco descenso o casi desaparecidas, que volvieron a emerger.

En el pasado, las enfermedades transmisibles fueron una importante causa de morbi-mortalidad, pero el descubrimiento en el último tercio del siglo XIX de sus agentes causales y el conocimiento de los reservorios, fuentes de infección, mecanismos de transmisión y factores de susceptibilidad llevaron al establecimiento de medidas preventivas con base científica que permitieron, conjuntamente con el desarrollo socioeconómico, disminuir de manera importante su incidencia y sobre todo su mortalidad en los países desarrollados.

Se inició el siglo XX con las luchas sanitarias en la confianza de que saneando, vacunando y aislando, las enfermedades transmisibles iban, en poco tiempo a dejar de suponer un problema de salud. Esto alentó a Harvey Cushing (1869-1939), a escribir en 1913, con referencia a la nueva situación social da Medicina: El doctor libra de la calleja de la cura, ha sido sustituido por el doctor onza de la calle de la prevención.

Con anterioridad a los años 70 los esfuerzos de la OMS y de los países desarrollados estuvieron dirigidos principalmente al control de las enfermedades transmisibles, obteniendo éxitos importantes entre los que destacan la eliminación del paludismo de amplias zonas del planeta y la erradicación mundial de la viruela, existiendo también el propósito de erradicar, antes de que finalice el siglo, la dracunculosis y la poliomielitis. Aunque potencialmente, podrían asimismo ser erradicadas las filariasis linfáticas, parotiditis, sarampión, teniasis solium y saginata y las cisticercosis, para la mayoría de las enfermedades infecciosas, la erradicación no es un objetivo realista.

En los años 70 y 80 disminuyó el interés y la atención prestada a las enfermedades transmisibles por los funcionarios de Salud Pública, médicos e investigadores, convirtiéndose las enfermedades crónicas degenerativas en el centro de su atención, en base a la errónea creencia de que las enfermedades transmisibles estaban vencidas, que eran algo que pertenecía al pasado, y al falso sentimiento de seguridad sobre los peligros suscitados por las enfermedades infecciosas, al que contribuyó la percepción equivocada de que los sofisticados sistemas asistenciales de 
los países desarrollados, con su conjunto de tecnologías médicas y el potente arsenal terapéutico, eran capaces de desarmar y resolver cualquier amenaza infecciosa.

Los resultados netos de estos cambios fueron una disminución en conjunto de los programas frente a las enfermedades transmisibles; el deterioro de los esfuerzos de vigilancia, olvidados en la priorización de las asignaciones presupuestarias, y una disminución de la pericia técnica frente a las enfermedades infecciosas tradicionales. Esta erosión de la infraestructura alrededor de las enfermedades transmisibles afectó directamente a la capacidad mundial para reconocer y responder frente a las nuevas enfermedades emergentes y reemergentes.

El sida vino a demostrar cuan equivocados estaban los que así pensaban y actuaban. Desde el comienzo de la pandemia en 1981 hasta el 20 de noviembre de 1996 se declararon a la OMS 1.544.067 casos de sida, si bien se estima en 8.400 .000 el número real de casos ocurridos en adultos y niños desde el comienzo de la epidemia, de los que corresponderían más del $75 \%$ a Africa; el $4 \%$ a Europa; el $7 \%$ a Latinoamérica y al Caribe; el $8 \%$ a los EEUU; el $6 \%$ a Asia, y menos del $1 \%$ a Australia y Nueva Zelanda.

El número de infectados a finales de 1996 se estimó en más de 22.6 millones de adultos y niños, y continúa aumentando de forma muy importante en los países de Africa subsahariana y del sur y sudeste asiático. En España hasta el pasado 31 de marzo se declararon 45132 casos, de los que ya fallecieron el 54.4\%. En 1996 se diagnosticaron 5.301 casos, estimándose la incidencia en 17 casos nuevos por 100.000 habitantes. El mecanísmo de transmisión más frecuente es el uso de drogas inyectadas (64\%) seguido por el heterosexual en las mujeres (33\%), y el homosexual en hombres $(14 \%)$.

No se cumplió el pronóstico que auguraba el final de las enfermedades transmisibles. Estamos acabando el siglo XX y mien- tras algunas disminuyen o desaparecen, surgen otras nuevas y aumentan algunas que se consideraban controladas.

Se descubren nuevos gérmenes, más de treinta en los últimos veinte años, productores de nuevas enfermedades o síndromes como la enfermedad de los legionarios que apareció en el verano de 1976 en Filadelfia, al tiempo que se erradicaba la viruela; la enfermedad de Lyme, la enfermedad humana transmitida por garrapatas más frecuente; el síndrome del choque tóxico; el sida; la hepatitis $\mathrm{C}$; el síndrome pulmonar por hantavirus que afectó al sureste de los Estados Unidos; la erlichosis humana; la fiebre hemorrágica venezolana; la angiomatósis bacilar; la fiebre hemorrágica brasileña; la fiebre hemorrágica por el virus Ebola en Africa, la variante de la enfermedad de Creutzfeldt-Jacob producida por el prión de la encefalopatía espongiforme bovina en el Reino Unido, y la colitis hemorrágica con síndrome hemolítico urémico debida a los E. coli enterohemorrágicos productores de toxinas similares a la shiga, de los que el prototipo es el E. coli 0157:H7 bautizado como el «bicho de las hamburguesas» (burger bug) por ser las hamburguesas y las carnes picadas de vacuno su vehículo más frecuente.

Resurgen con fuerza enfermedades como la tuberculosis en Estados Unidos; el cólera eltor en Iberoamérica, continente al que no visitaba desde hacía cien años, produciendo desde 1991 más de un millón de casos y 10.000 defunciones, y en Africa 555.000 casos y 33.000 defunciones, y por un nuevo biotipo, el vibrión colérico O139, en Asia. La peste en la India, cuando se acababan de cumplir cien años del descubrimiento de su agente causal por Yersin, con escenas que nos hicieron recordar el precepto salernitano Hoec tria tabificam tollunt adverbia pestem: Mox, longé, tardé, cede recede, veni (tres adverbios son los que libran de toda peste: sal pronto, vete lejos y regresa tarde. La fiebre amarilla en Kenia; la fiebre del Valle del Rift en Egipto; la Shigella dysenterie multidrogorresistente en Burundi; el dengue en 
centro y sur América, con 240.000 casos en 1995, y en Australia; la fiebre hemorrágica boliviana en Bolivia; la fascitis necrotizante en Europa, y la meningitis C en Estados Unidos, Canada, Reino Unido, Chequia y España.

Enfermedades prevenibles por vacunas como la difteria y la poliomielitis están afectando nuevamente a territorios que llevaban muchos años libres de dichas enfermedades, debido a descensos en las coberturas vacunales por desabastecimiento de vacunas a causa de la penuria económica y crisis social, es el caso de los Nuevos Estados Independientes de la antigua Unión Sovietica; ó por oposición a la vacunación de minorías étnicas como la gitana en Bulgaria en 1991, ó de comunidades religiosas en Holanda y Malasia en 1992, y en Canadá en 1993; ó por fallos en la cadena de frío junto con problemas de saneamiento e incremento de la movilidad de la población, conjunto de factores responsables del brote de Albania en 1996.

Enfermedades clásicamente consideradas no infecciosas se descubre que lo son; es el caso de la gastritis tipo B, la úlcera duodenal y el cáncer gástrico en las que tiene un papel etiológico destacado el Helicobacter pílori. El cáncer de cuello de útero asociado con los papilomavirus humanos transmitidos sexualmente. El virus de la hepatitis C, identificado en 1989, es hoy una de las principales causas de enfermedad hepática crónica, cirrosis y cáncer de hígado, ocasionando también enfermedades extrahepáticas como la glomerulonefritis membrano-proliferativa, crioglobulinemia mixta esencial y porfiria tarda. Las infecciones por clamydias, implicadas desde hace tiempo en la infertilidad, fueron en estos años pasados asociadas con lesiones arterioesclcróticas de las arterias coronarias, y hantavirus vehículados por ratas pueden jugar un papel en la etiología de la enfermedad hipertensiva renal.

Reaparecen enfermedades exóticas en países desarrollados, tal es el caso de la enferme- dad de Chagas, de la que se han producido casos en Estados Unidos y Canadá, transmitida por transfusiones de sangre procedente de inmigrantes de países sudamericanos, en donde la enfermedad es endémica, o de la malaria ya sea la denominada malaria aeroportuaria, casos autóctonos de malaria transmitida por mosquitos tropicales importados por vía aérea que afectan a personas que viven o trabajan en el entorno de un aeropuerto internacional en un área libre de esta enfermedad, de los que en Europa se describieron al menos 34 casos, o por reintroducción de la malaria en áreas donde se tenía erradicada como el sur de California y Florida.

Aparecen y se incrementan las resistencias a los antibióticos a causa de su amplio y mal uso, y aumentan las infecciones en pacientes con resistencia disminuida.

El incremento de las enfermedades infecciosas, que suponen el $25 \%$ de todas las consultas médicas al año, amenaza la salud pública y contribuye de modo importante al aumento de los costes de la atención sanitaria. A nivel mundial continuan siendo la principal causa de muerte y en los Estados Unidos responden directamente de tres, e indirectamente de cinco, de las diez principales causas de muerte, contribuyendo significativamente a las muertes asociadas con el cáncer y con la enfermedad pulmonar obstructiva crónica (EPOC), sin embargo, la carga de las enfermedades infecciosas, es probablemente subestimada. Por ejemplo, la Clasificación Internacional de Enfermedades, incluye enfermedades infecciosas en otras categorías, escondiendo su impacto en la salud pública; así las endocarditis están clasificadas dentro de las enfermedades cardiovasculares, y las meningitis e infecciones del oído medio en las enfermedades del sistema nervioso y órganos de los sentidos, respectivamente.

Los grupos de población con mas riesgo de sufrir infecciones son las personas que tienen su inmunidad disminuida, en las que son particularmente graves; los ancianos; las 
personas que están siendo atendidas en instituciones tales como hospitales y residencias, pcrsonas con deficiente acceso a la atención sanitaria, como vagabundos, temporeros agrícolas y otros colectivos de bajo estatus socioeconómico, y los niños atendidos en guarderías cuyo número aumentó en la pasada década al tiempo que las madres jóvenes se integraban en el trabajo.

La emergencia y reemergencia de estas enfermedades está influenciada además de por el deterioro, antes comentado, de la infraestructura de la salud pública, por los cambios demográficos, crecimiento de la población y cambios en su estructura etária, densidad y distribución; los cambios de conducta como la promiscuidad sexual y el consumo de drogas; los avances médicos con prácticas diagnósticas y terapéuticas más agresivas e incrementada utilización de prótesis y catéteres; los avances tecnológicos e industriales; las alteraciones ecológicas, tales como la deforestación y reforestación; los viajes con movimiento de gentes y microbios de una región a otra; el transporte internacional de mercancias, en especial animales infectados, y los cambios y adaptaciones.

El Center for Disease Control (CDC) a raíz de unos informes que llamaron la atención sobre el tema, elaborados a principios de los años 90 por Comités de Expertos convocados por el Instituto de Medicina de la Academia Nacional de Ciencias de los Estados Unidos, ha comprendido que para detectar y prevenir de forma efectiva las enfermedades emergentes son necesarias una serie de mejoras en los sistemas de salud pública, el diseño de programas e infraestructua sanitaria y establecer una interrelación, cooperación y coordinación entre un amplio rango de organizaciones públicas y privadas. Para afrontar este reto ha diseñado una estrategia de prevención plasmada en el documento: «Addressing emerging infectious disease threats. A prevention strategy for the United States", publicado en 1994.
Dicha estrategia pretende alcanzar cuatro grandes metas: Detectar rapidamente, investigar y monitorizar los patógenos emergentes, las enfermedades que ellos causan y los factores que influencian su emergencia; integrar los laboratorios de investigación y los epidemiológicos a fin de optimizar la práctica de la salud pública; intensificar la comunicación de información de salud pública sobre las enfermedades emergentes asegurando la rápida puesta en práctica de estrategias preventivas, y fortalecer las infraestructuras de salud pública para el soporte de la vigilancia epidemiológica y puesta en práctica de programas de prevención y control en los distintos niveles de la organización administrativa.

Los gérmenes patógenos no respetan los límites nacionales, y como decía Ledeberg en 1988, «el germen que ayer mató a un niño, en un lejano continente, puede afectarnos hoy a nosotros y dar lugar mañana a una pandemia mundial», por ello su prevención y control requiere un enfoque mundial, lo que cae de lleno en las competencias de la OMS que, consciente de la importancia de este problema y de sus responsabilidades, organizó en Ginebra en abril de 1994 una reunión de expertos en la que elaboró un plan de acción con cuatro grandes objetivos: Fortalecer la vigilancia mundial de las enfermedades infecciosas; fortalecer la infraestructura internacional necesaria para dicha vigilancia manteniendo y reforzando las capacidades de los laboratorios y formando $\mathrm{y}$ entrenando al personal; crear un programa de investigación aplicada, y fortalecer la capacidad internacional para la prevención y control de las enfermedades infecciosas, mediante el desarrollo de protocolos de prevención y control, de recomendaciones para minimizar el impacto de la resistencia microbia y mejora de los medios de comunicación y difusión de la información.

En el conjunto de todas estas estrategias observamos que la vigilancia epidemiológica ocupa el lugar más destacado por ser lo básico, lo fundamental. Conocer en tiempo 
real lo que ocurre, es necesario para actuar rapidamente de la forma más adecuada.

Por ello no es de extrañar que la OMS eligiese el lema enfermedades infecciosas emergentes «Alerta mundial, respuesta mundial», para celebrar este Día Mundial de la Salud. Su mensaje pretende sensibilizar a las autoridades sanitarias de la importancia de los sistemas de vigilancia de salud pública en el control de las enfermedades emergentes, sistemas erróneamente olvidados en los últimos años en la priorización de las asignaciones presupucstarias.

El principal objetivo de los sistemas sanitarios deber ser evitar la aparición de las enfermedades, por ello la implantación de medidas preventivas debe asumirse como una prioridad, y dentro de ellas la vigilancia de salud pública es fundamental. Pero esto no se improvisa, exige un trabajo de tiempo, una puesta a punto de todo el sistema sanitario, en el que la elaboración de protocolos, su consenso y su difusión son fundamentales. Actuar informados y todos del mismo modo, son algunas de las claves del éxito. Por el desarrollo y modernización de los sistemas de información y vigilancia de salud pública es prioritario y urgente.

La difusión de la información sobre la situación de salud y sus determinantes forma parte del núcleo básico de las funciones de la salud pública, a fin de implicar tanto a los decisores de las políticas sanitarias como a los propios profesionales sanitarios en la lucha contra estas enfermedades, para lo que es preciso estar informado y conocer sus principales aspectos epidemiológicos, diagnósticos, terapéuticos y preventivos.

Frente a las enfermedades infecciosas emergentes y reemergentes existe una gran sensibilización cada vez mayor en todos los ámbitos, y en el científico la literatura sobre el tema es cada vez más abundante artículos y libros. Una prueba de ello es que en febrero de 1995 comenzó a editarse una nueva revista dirigida especificamente a este tema "Emerging infectious diseases» a la que se puede acceder a través de Internet. 